\title{
DESIGNING RESEARCH METHODOLOGY FOR DISTRIBUTION OF NON-METALLIC INCLUSIONS IN LIQUID STEEL DURING ITS FLOW THROUGH TUNDISH
}

\author{
${ }^{1}$ Tomasz MERDER, ${ }^{2}$ Marek WARZECHA, ${ }^{1}$ Jacek PIEPRZYCA, ${ }^{2}$ Artur HUTNY \\ ${ }^{1}$ Silesian University of Technology, Faculty of Materials Engineering and Metallurgy, Katowice, Poland, EU, \\ tomasz.merder@polsl.pl \\ 2University of Technology, Faculty of Production Engineering and Materials Technology Czestochowa, \\ Poland, EU warzecha@wip.pcz.pl
}

https://doi.org/10.37904/metal.2019.790

\begin{abstract}
The research work is a part of a larger study on identifying distribution of microparticles in the model liquid, which flows through a model of the tundish. Model (physical) testing is aimed at qualitative (based on visualization of the process) and quantitative assessments (performed by using the Abakus ${ }^{\circledR}$ Mobil Fluid laser microparticle counter).

The article presents methodology on preparing microparticles for research tests and research test findings performed by using a laser microparticle counter. These tests were aimed at developing correct methodology for collecting samples in the tundish model, as well as, for their analysis by using a measuring instrument a laser particle counter.
\end{abstract}

Keywords: Tundish, non-metallic inclusions, distribution, physical modelling

\section{INTRODUCTION}

The metallurgical purity is determined by technological and mechanical properties of the manufactured steel. These, in turn, depend to a large extent on the non-metallic inclusions (NMIs) contained therein, and more specifically on their: size, type, chemical and phase composition or concentration. None of modern metallurgical techniques allow for production of steel free of inclusions. Reduction of the amount of NMls is only possibly in the steel. This is explained in particular by the insightful interest in NMls and undertaking by numerous research centres the possibility of removing NMIs being produced in steel during its manufacture processes. Numerical [1-4] and physical modelling [5-7] are commonly used as research methods.

The review of literature tailored to the subject matter [5-11] shows that the most commonly used as model particles (NMI models) are used globular, hollow, coated or uncoated glass microspheres. Particles from various polymers are also used. It is expected that the buoyancy forces and the dynamics of their motion in the model liquid will be similar to the behaviour of NMIs in an industrial tundish.

The authors of the papers [6,7] - by investigating the mechanism of NMI removal by inert gas flotation in model determinations - used polystyrene (PS) microparticles with a density of $1020 \mathrm{~kg} \cdot \mathrm{m}^{-3}$. It is evident that in both cases, materials with similar properties were used; wherein the density of microparticles was similar to that of the model liquid, namely water.

The mechanism of removing NMls from liquid steel by inserting gas bubbles was also a subject of research study in [5], however, two types of microparticles were used for model tests. The first of them were silver coated hollow glass (SCHG) microspheres with a density of $465 \mathrm{~kg} \cdot \mathrm{m}^{-3}$, while the other are made of plastic with a density of $1440 \mathrm{~kg} \cdot \mathrm{m}^{-3}$. For SCHG particles the ratio of their density to water density is almost the same as for NMI particles and liquid steel. However, plastic particles with the density of 1.5 times greater than the density of water will behave in the opposite manner in the flow test system; their flow towards the liquid surface will not be spontaneous, because they will be subject to sedimentation. 
The performed literature review indicates that various types of particles can be applied, however, it should be bear in mind, and that during the analysis on transferring research results into real conditions, and appropriate recalculations should be undertaken.

\section{CHARACTERISTICS OF THE MEASURING INSTRUMENT}

The research testing was carried out in segments by using the COS water model [12]. The rules of similarity [13] are satisfied explicitly in the main segment. Other segments play the role of assisting elements. Its main segment consists of a tundish model designed in the $S_{L}=1: 4=0.25$ scale. It is a two-strand trough-type tundish.

Equipping the model with „Abakus $₫$ Mobil Fluid” measuring instrument manufactured by Markus Klotz GmbH is a pioneer solution [14]. Products of this company are considered as a comparative pattern in experimental two-phase flows. This device is used to measure the amount and size of microparticles in a liquid. The laser particle counter system consists of a laser sensor coupled with a computer through which a mixture of water and microparticles flows. The sensor is integrated with a pump that operates independently of the inlet pressure. The light source of the monochromatic sensor is a laser diode and its receiver is the CCD screen. Microparticles flowing through the system are blocking the laser light, which reaches the screen. The signal received by the CCD sensor is analysed and on this basis the diameters of the microparticles are determined [14]. The operation scheme for this device and its view are shown in Figure 1.

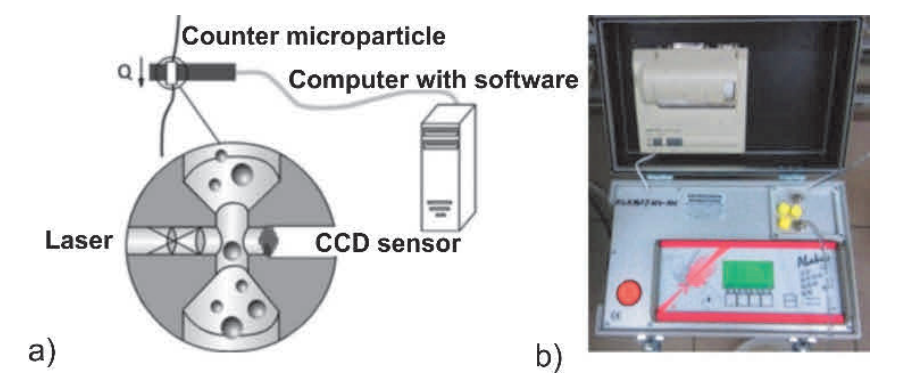

Figure 1 Laser microparticle counter „Abakus ${ }^{\circledR}$ mobil fluid”: a) sketch of operation in the measuring system [14],

b) view of the device

The LDS $30 / 30$ sensor used in the counter works correctly even at very high concentrations of solid particles in the liquid. The maximum concentration amounts to 120,000 particles per one millilitre of fluid. The LDS sensor has a high reproducibility rate and is characterized by good resolution. The measuring system complements the specialized software.

\section{PREPERATION OF MICROPARTICLES FOR TESTING}

In the research study, the authors used microparticles of hollow glass bubbles manufactured by Scotch $3 \mathrm{M}$ [15] (Table 1). They reflect laser light and have a shape factor value close to unity. Numerous research model tests indicate that the use of spherical microparticles in the research study is not an excessive simplification, which could prevent disclosure of the essence of the phenomenon.

Table 1 Parameters of Scotch 3M microparticles used in the experimental research testing [15]

\begin{tabular}{|c|c|c|}
\hline $\begin{array}{c}\text { Density } \\
\left(\mathbf{k g} \cdot \mathbf{m}^{-3}\right)\end{array}$ & $\begin{array}{c}\text { Diameter } \\
(\mu \mathrm{m})\end{array}$ & $\begin{array}{c}\text { Relation density of microparticles and water } \\
(-)\end{array}$ \\
\hline 120 & $1 \div 140$, average $17 \div 70$ & 0.1202 \\
\hline
\end{tabular}

Theses microparticles fulfil the similarity requirements and can be used for modelling the behaviour of NMIs in liquid steel. The first stage of the study was to sift microparticles to fractionate them into selected dimensional ranges. For this, a pneumatic-mechanical screen LPzE-2e/B-2e [16] was used (Figure 2) manufactured by MULTISERW, which was equipped with relevant and certified analytical sieve system. 

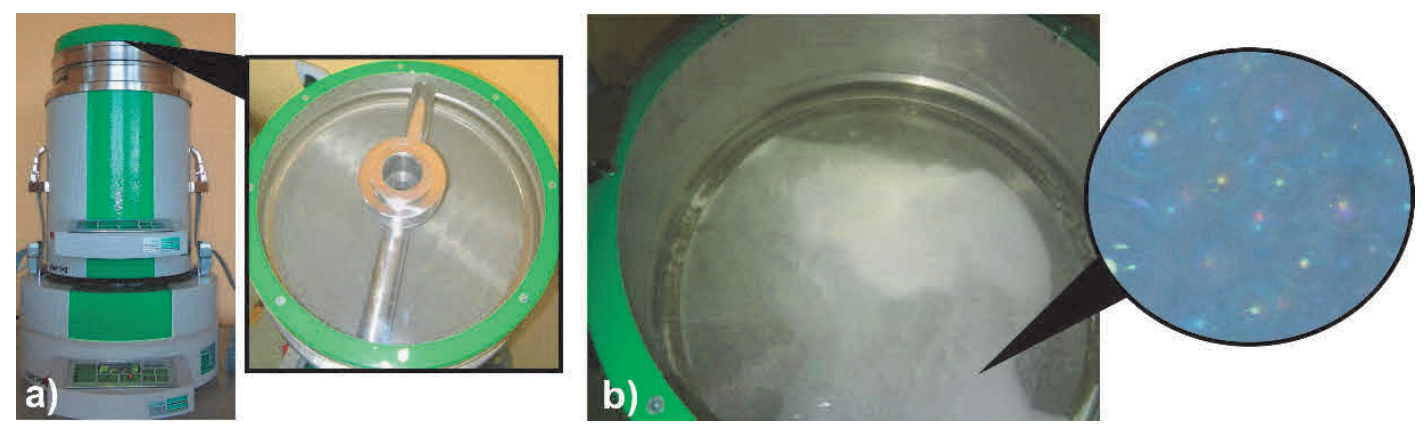

Figure 2 Pneumatic-mechanical apparatus for sieving LPzE-2e/B-2e:

a) view b) screening module during operation

Prior to fractionation of microparticles - based on preliminary testing with optical microscopy - proper program for running the device (apparatus) was set up and adequate values of its operational parameters were determined. After each screening operation, there were monitored outcomes and the quality of microparticles by using Nikon ECLIPSE E200 led binocular microscope [17] equipped with DS-Fi1 camera [18]. The process of sieving was time-consuming due to the fact that improper test settings (too intensive vibrations and too high working pressure) caused damage in microparticles. In fine fractions of particles could be found fragments of microparticles being crushed during the process (see Figure 3 ).
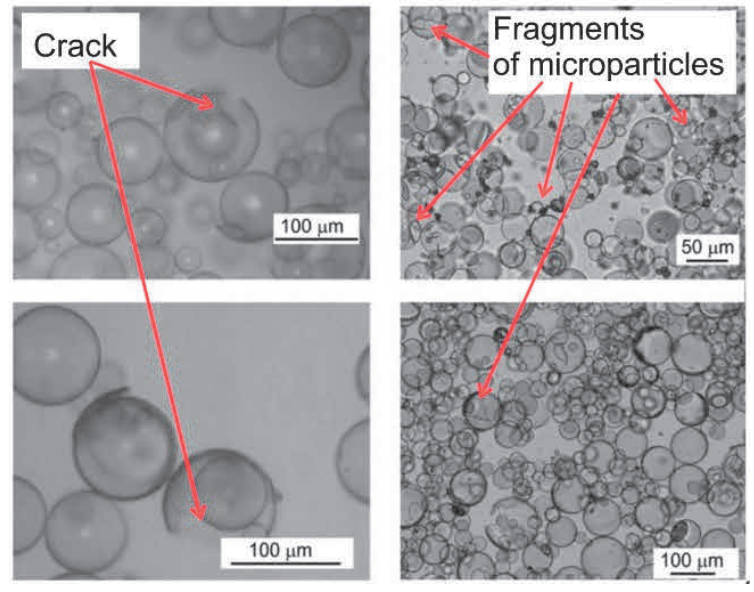

Figure 3 Microparticles damage as a result of improper sieving (magnification $5 x \div 20 \times$ )

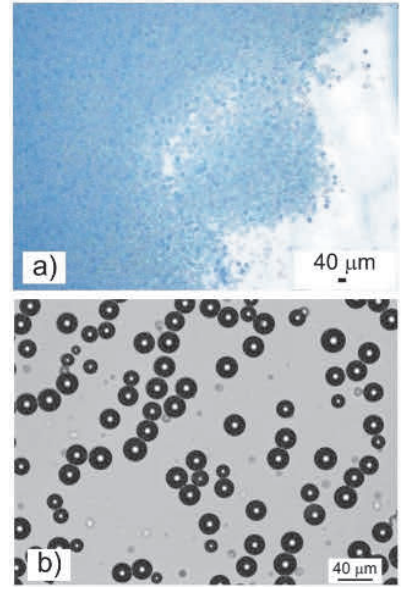

Figure 4 View a) Microparticles after sieving $5 \times$, b) Prepared mixtures of microparticles and water $10 \times$

Finally, after many tests, such operating parameters were selected for the process of sieving, which ensured correct results. The developed methodology allowed to obtain the expected fractions, consistent with the assumed research study on the physical model being approx. $80 \%$ efficient. Fractions of microparticles (Figure 4a) within the size of 10 to $140 \mu \mathrm{m}$ were prepared.

In order to introduce microparticles into the research model system of tundish, it was required to prepare a mixture consisting of these particles and water. Components of the mixture were selected in such a proportion so it will be free of the supply pipe clogging risk and counting of its particles will be possible by using a laser counter.

In order to ensure water-wetting of glass microparticles, a small amount of the substance reducing its surface tension was introduced. A mixture of $0.5 \mathrm{~g}$ microparticles and water $(4.3 \mathrm{~kg})$ was prepared for each fraction. Such amount allows for introducing the mixture of microparticles into the tundish model throughout the duration 
of the experiment. Figure $4 \mathrm{~b}$ shows a particle fraction of $20 \mu \mathrm{m}$ collected from a (water and microparticles) mixture prepared for model tests.

Two phase mixture with the abovementioned composition of water and microparticles was intensively mixed, by using a mechanical agitator, for a period of 10 minutes, prior to performing the experiment. This procedure allowed to achieve the expected

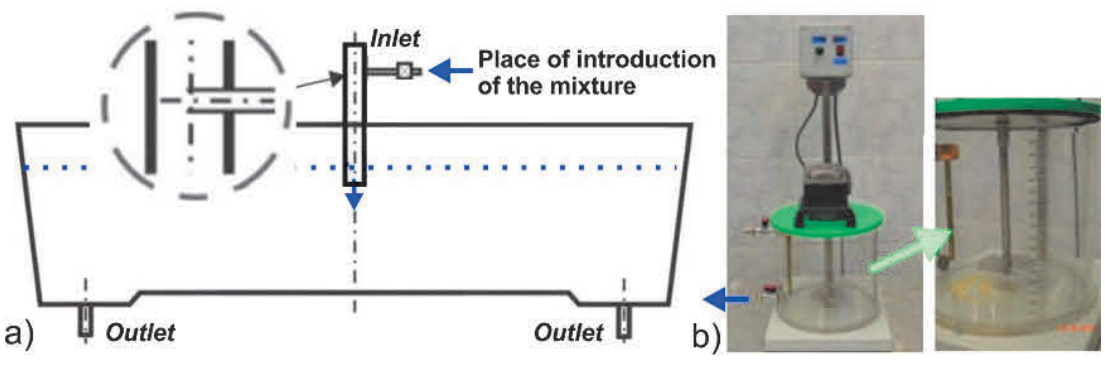
homogenization of microparticles in the water.

\section{RESEARCH TEST RESULTS}

The complexity of the research tests being performed by using a laser particle counter evoked the decision to undertake many preliminary tests before to the primary research test were launched. These tests were aimed at developing the correct methodology of sampling from the tundish model and performing analysis of the samples by using a measuring device - a laser particle counter. Preliminary measurements consisted of two stages, namely:

- $\quad$ purity analysis of water being used in research tests in order to reveal the size and amount of contaminants that are already present in it;

- $\quad$ testing the laser particle counter to ensure the objectivity of the results obtained for various concentrations of microparticles in the sampled mixture consisting of water and microparticles.

The first part of the research study performed by using a laser particle counter concerned on determining the purity of water used in experiments. The research was aimed to analyse the size and amount of impurities that are present in filtered water (used in research) in order to eliminate potential measurement errors associated therewith. The supplier (feeder) of the hydraulic system was equipped with a system of cleaning filters in order to reduce the amount of impurities in the size of above $5 \mu \mathrm{m}$. Dozens of test measurements were carried out for various working times of the filters (during their usage).

Average results corresponding to 50 measurement are indicated in Figure 6. Analysis of the results (Figure 6) clearly indicates that filters installed in the hydraulic system serve the requirement well and definitely retain most of the impurities in the size above $15 \mu \mathrm{m}$. The amount of impurities in the measurement ranges of the scheduled research tests is insignificant and it will not cause errors in measurement results.

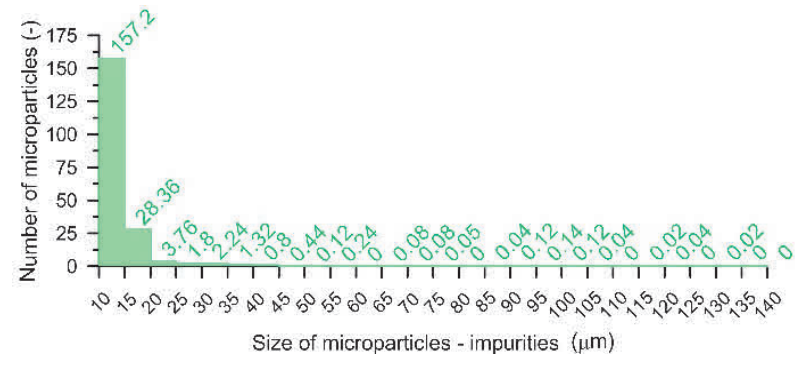

Figure 6 Average results of measurements made for water used in investigations

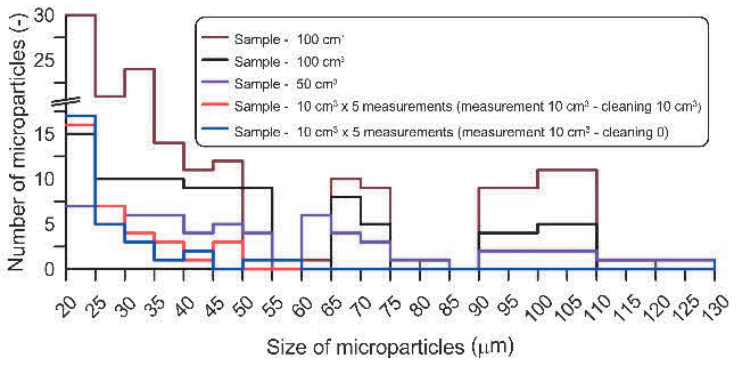

Figure 7 Test results of filtered water for different sample volumes 
When the amount of microparticles in the mixture is significant - for fraction of $10 \mu \mathrm{m}$ the number of microparticles reaches approx. $2.262 \cdot 10^{7}$ - the measured number of microparticles in water is negligible for the performed measurements.

The second part of the research study focused on testing laser counter for repeatability of results obtained for samples with variable volume. The sample volumes has ranged from 10 to $200 \mathrm{~cm}^{3}$. Various types of liquids were used, namely: filtered water, distilled water and (water-microparticle) mixture. Distilled water was always used for raising the measuring system before the next designation was performed. Measurement results obtained for filtered water are demonstrated in Figure 7. Analysis of the obtained results (see Figures 6 and 7 ) allows for raising the statement that the quantity measurement of microparticles should be performed for the optimal sample volume. For the purpose of designation, a sample in the volume of $>10 \mathrm{~cm}^{3}$ should be collected. Even if the measurements will be repeated many times, for samples of $10 \mathrm{~cm}^{3}$, the number of particles is slightly raised.

An example of a comparison of measurement results for mixture of water and microparticles is shown in Figure 8.

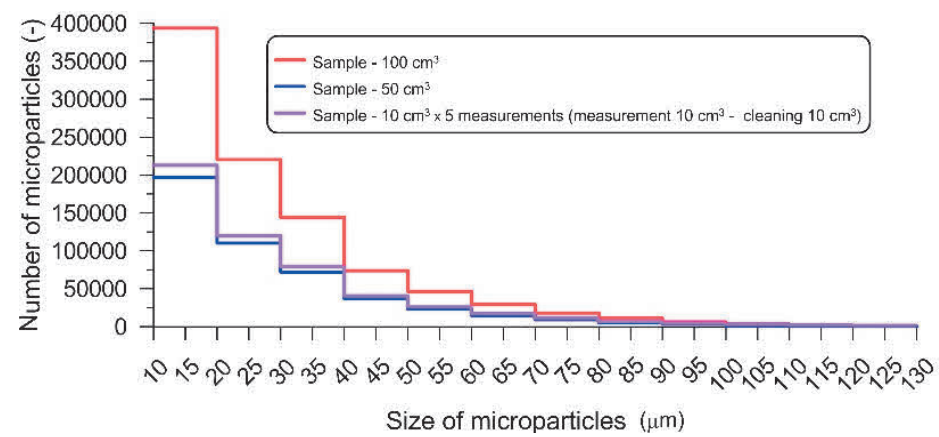

Figure 8 Test results for a mixture of microparticles and filtered water at different sample volumes [19]
The presented results clearly show that - similar as it was in the case of water based measurements - even when the measurements are repeated many times, in case of measurements for the volume of $10 \mathrm{~cm}^{3}$, slightly raised values of microparticles are obtained. For sample volumes of $50 \mathrm{~cm}^{3}$ and $100 \mathrm{~cm}^{3}$ the results are similar.

\section{CONCLUSIONS}

Based on the conducted research tests, the following can be stated:

- $\quad$ The assumptions made to the model based research are met by the hydraulic system, being designed for introducing into the tundish model of two-phase mixture, consisting of water and glass microparticles. It facilitates dosing of the mixture in an exact place, namely in the axis of the stream flowing into a model of the tundish.

- Filters installed in the hydraulic system reliably fulfil their role and effectively retain most of the contaminates grater then $15 \mu \mathrm{m}$.

- $\quad$ Speaking of measurement ranges of the scheduled research tests, the amount of contaminants found in water used for research tests is insignificant and it will not affect the measurement results in terms of causing research errors.

- $\quad$ The minimum volume of the taken samples is $50 \mathrm{~cm}^{3}$. It is at the same time the optimal value in terms of measurement accuracy and laser counter measurement time.

- During performance of a continuous measurement, in order to ensure correctness of the inference, it is required to rinse the device (laser particle counter) between each measurement by using at least $10 \mathrm{~cm}^{3}$ of filtered or distilled water. 


\section{ACKNOWLEDGEMENTS}

This paper was created with the financial support of the Project No. 2013/09/b/st8/00143. Project funded by the National Science Centre of the Poland (from which the researches was carried out).

This paper was created with the financial support of Polish Ministry for Science and Higher Education under internal grant BK-205/RM0/2019 for Faculty of Materials Engineering and Metallurgy, Silesian University of Technology, Poland.

\section{REFERENCES}

[1] RAMOS-BANDERAS, A., MORALES, R.D., BARETTO, J., SOLORIO-DIAZ, G., Modelling study of inclusions removal by bubble flotation in the tundish. Steel Research International, 2006, vol. 77, no. 3, pp.325-335.

[2] CHATTERJEE, D., MAZUMDAR, D., PATIL, S.P., Physical and mathematical modelling of two-phase flow in a hollow jet nozzle. Metallurgical and Materials Transactions B, 2007, vol. 38, no. 5, pp. 819-831.

[3] WARZECHA, M., MERDER, T., WARZECHA P., Effect of the structural parameters changes in the multi-strand tundish on the non-metallic inclusions distribution and separation, Metalurgija, vol. 53, no. 4,2014, pp. 439-442.

[4] JHA, P.K, RAO, P.S., DEWAN, A., Effect of height and position of dams on inclusion removal in a six strand tundish. ISIJ International, 2008, vol. 48, no. 1, pp. 154-160.

[5] KNOW, Y., ZANG, J., LEE, H.G., Water model and CFD studies of bubble dispersion and inclusion removal in continuous casting mould of steel. ISIJ International, 2006, vol. 46, no. 2, pp. 257-266.

[6] YANG, H.L., HE, P., ZHA,I Y.CH., Removal behavior of inclusions in molten steel by bubble wake flow based on water model experiment. ISIJ International, 2014, vol. 54, no. 3, pp. 578-581.

[7] ZHANG, Q.Y., WANG, L.T., ZHI, R., A new method of removing inclusions in molten steel by injecting gas from the shroud. ISIJ International, 2006, vol. 46, no. 8, pp. 1177-1182.

[8] ROGLER, J.P., HEASLIP, L.J., MEHRVAR, M., Physical modeling of inclusion removal in a tundish by gas bubbling. Canadian Metallurgical Quarterly, 2005, vol. 44, no. 3, pp. 357-368.

[9] MARTINEZ, B.E., MAEDA, M., HEASLIP, L.J., RODRIGUEZ, G., MCLEAN, A., Effects of fluid flow on the inclusion separation in continuous casting tundish. ISIJ International, 1986, vol. 26, no. 8, pp. 724-731.

[10] HOJO, M., NAKAO, R., UMEZAKI, T., Oxide inclusion in ladle and tundish for producing clean stainless steel. ISIJ International, 1996, vol. 36, no. 4, pp. 128-131.

[11] MURAKATA, Y., SUNG, M.G., SASSA, K., ASAI, S., Visualization of collision behavior of participle simulating inclusions in a turbulent molten steel flow and is theoretical analysis. ISIJ International, 2007, vol. 47, no. 3, pp. 633-637.

[12] MERDER, T., Numerical analysis of the structure of liquid flow in the tundish with physical model verification, Archives of Metallurgy and Materials, 2018, vol. 63, no.4, pp. 1895-1901.

[13] MICHALEK, Karel. The use of physical modeling and numerical optimization for metallurgical processes. Ostrawa: Publishing of the Vysoka Skola Banska, 2001. p. 62.

[14] Information materials Markus Klotz GmbH 2018. Available from http://www.fa-klotz.de.

[15] Information materials 3M_Glass-Bubbles 2018. Available from http://www.3m.com/3M/Glass-Bubbles.

[16] Information materials Multiserw-Morek 2018. Available from http://multiserw-morek.pl.

[17] Information materials Nikon instruments Eclipse-E200-LED 2018. Available from https://www.nikoninstruments.com/Eclipse-E200-LED.

[18] Information materials Nikon instruments High-Definition Color Camera Head 2018. Available from https://www.nikoninstruments.com/Ds-Fi1

[19] MERDER, Tomasz. Numerical and physical modelling of non-metallic inclusions distribution during the flow of liquid steel by cc tundish. Gliwice: Publishing of the Silesian University of Technology, 2018. pp. 105-113.

[20] WARZECHA, M., HUTNY, A.M., MERDER, T., JĘDRYSIAK, B., Methodology of inclusions removing from steel flowing through the tundish. Metalurgija, 2016, vol. 56, no. 3-4, pp. 291-293. 